\title{
The Importance of Global Financial Indices for Investors in Alternative Investment
}

\author{
Josef Novotný ${ }^{1, *}$, and Iveta Jaklová ${ }^{1}$ \\ ${ }^{1}$ University of Pardubice, Faculty of Economics and Administration, Institute of Business Economics \\ and Management, Studentská 95, 53210 Pardubice, Czech Republic
}

\begin{abstract}
Research background: One of the financial market indicators are very important global financial indices. These express the state and development of the market for certain investment instruments that form the basis of an index. These international financial indices are used to facilitate the process of making investment decisions for investors. Global equity indices are mainly popular with the investing public. However, global indices of alternative investments are less popular. The main problem with alternative investments is their low awareness among the investing public, including the fact that many investors are unable to assess their strengths and investment potential, which can lead to an increase in their assets. Some alternative investments are gaining in popularity especially in times of world financial crises, uncertainty and economic recessions, when their prices tend to rise as investors seek a safe haven to value or protect their free cash, especially from inflation.

Purpose of the article: The aim of the article is to draw attention to the importance and advantages of selected alternative investment with the support of financial indices in the global environment, which is whiskey.

Methods: Methods of analysis, comparison and synthesis were used in the article. The principles of logical thinking were also used to achieve the goal, especially in the application of scientific methods that follow each other.

Findings \& Value added: The main finding was that the examined international alternative indices focused on whiskey performed higher than the global equity financial indices in the monitored period.
\end{abstract}

Keywords: Global financial indices; Investor; Alternative investment; International financial market

JEL Classification: $G 10 ; G 11 ; G 15$

\footnotetext{
*Corresponding author: josef.novotny@upce.cz
} 


\section{Introduction}

In today's globalized world, it is important to have key information to succeed in the world of international investments. Financial indices are one of the tools that is offered and which facilitates investors' decisions. Global stock indices which have an international influence are especially popular with the investing public. According to Chen et al. [1], these include the following financial indices: IXIC, FTSE, GDAXI, GSCP and KS11. This is due to the fact that stocks are the most widespread security and have a long history. This is evidenced by the Dow Jones Industrial Average, which was founded in 1896 and has had more than a century of history that continues to this day. Many alternative investments lack this attribute, including whiskey. This is a certain pitfall that an investor must take into account in investing plans.

The aim of the article is to draw attention to and explain the importance and advantages of the selected alternative investment, which is whiskey with the support of financial indices in a global environment. With emphasis on its appreciation in defined time intervals with the support and analysis of the historical performance of selected indices related to this non-traditional investment, including its comparison with major stock indices that have an international character.

The main problem associated with most alternative investments, and this also applies to whiskey, is their low awareness among the investing public and the existence of only a small and limited circle of investors who have sufficient experience with some of these investments. Furthermore, many potential investors are unable to assess their strengths and investment potential, which may lead to an increase in their assets. This is due to insufficient and often limited information and experience, which is lacking in the general public.

Given the current situation in the world, some alternative investments are beginning to gain international popularity, especially in uncertain times, when there is talk of global financial crises, economic recessions and social uncertainties caused by, for example, the ongoing coronavirus pandemic. In such a situation, investors who have sufficient financial capital are looking for the best way to protect and enhance their free cash resources. One of the solutions is to invest in alternative investments and thus reduce the risk in the composition of investments.

A certain pitfall related to non-traditional investments is that there is a lack of highquality comprehensive book resources focused on investment opportunities. It is usually information that is not developed in detail. An investor must somehow compile the knowledge from various available sources in order to obtain more detailed information about a possible investment plan.

Kleine et al. in [2] dealt with a research aimed at alternative investment investors. One of the research questions addressed by the authors was why investors create and invest in collections of alternative investments. These authors came to the interesting finding that individuals who create collections with a partial investment motive have an above-average education and have sufficient financial resources to be able to carry out investment plans for non-traditional investments. It also allows them to gain and expand new investment experience in financial markets. The importance of alternative investments in portfolios is pointed out by Platanakis et al. [3], which argues that the popularity of these investments is beginning to be similar to stocks, mainly due to the reduction of risk in investment plans. On the other hand, these authors pointed to the negative of alternative investments in stock and bond portfolios in the US financial market, which is due to the risk of future estimates of how these non-traditional investments will develop. The prediction of alternative investments in time series was dealt with Lahmiri et al. [4], using the IGARCH model. In contrast, the prediction of financial health of companies, as a form of standard investment, 
is dealt with by many more authors, for example at the level of bankruptcy models, namely; Alaka et al. [5], Kraftová and Kašparová [6], Kuběnka and Myšková [7], Kuběnka [8].

The issue of alternative investments and pension funds has been examined by Defau and De Moor [9], which draws attention to the fact that the allocation of assets by pension funds and institutional investors to alternative investments has increased. In the pension fund industry, they point out two main reasons why interest in alternative investments is increasing. The first reason concerns low interest rates and the second has an impact on diversification in investors' portfolios. The latter influence is also supported by Bernardo and Campani [10]. Due to the low returns on traditional investments such as stocks and bonds, it forces investors to take more risks or look for new areas of investment that will bring investors the desired returns. Alternative investments are one of the areas in which there has been an increase in interest from the investing public. The growth of interest in alternative investments in the USA, but also in general at the international level, has increased. This finding is confirmed by Kräussl et al., [11]. These include, for example, real estate, collectibles and commodities, which mainly represent precious metals, as these can be physically owned by an investor.

As already mentioned, financial indices and their development are important for investors, because they facilitate investment decisions for investors. The issue of financial indices with a focus on alternative investments has been dealt with Lahmiri and Bekiros [12]. Commodities are close to alternative investments, as some of them have the same characteristics as some alternative investments. These are mainly precious metals that serve as protection against inflation in times of uncertainty. This is seen even today when the prices of precious metals are rising. Indices are key in almost all industries. This is evidenced by the newly designed natural gas price index (NGPI) for the entire Chinese market for this commodity. [Yang et al., 13] It is an important energy raw material with future market potential as its global application is expanding. In the Czech market environment, there was an absence of a land price index. This domestic index was designed and compiled according to Novotný and Myšková [14], which facilitates decision-making for investors as well as potential applicants for this key production factor. Indices are used for comparisons and analyses. An example is the research of the authors [Manavi et al., 15], who examined the behaviour of cryptocurrencies, whether they show attributes as real currencies or as commodities. The subject of the research was seven cryptocurrencies, 28 currencies trading on FOREX, 2 commodities and just 5 indices, where two were commodity and three financial indices.

\section{Methods}

Several scientific methods were used in the article to achieve the stated goal of the article. The first of the methods was the analysis that was used in the search of literary and Internet sources related to the researched issue, concerning global stock financial and alternative indices for the examined investment, which is whiskey. This method was supplemented by a synthesis in connecting knowledge obtained from available literary and Internet sources. This is followed by the method of comparison, which was used to compare international financial indices and indices for whiskey. Furthermore, the principles of logical thinking and logic were applied, especially in evaluating the historical performance of selected indices, comparison and analysis of financial indices for the selected time period. 


\section{Results}

As turbulent changes in financial markets often occur, the behaviour of investors seeking safe investments with investment potential changes as well. Alternative investments, including whiskey, has become one of the areas of interest. It is a global alcoholic beverage with a long tradition, but its investment tradition, including indices related to this commodity, is not as popular as stock indices. Although whiskey is a distillate with a rich international history around the world, information on investing in this popular commodity is far from such a reputation. Despite the fact that it is estimated that this beverage was produced, mostly illegally, already in the 5th century AD. Although the history of this distillate has been really long and rich, the first global whiskey fund was not established in Hong Kong until 2014 and another in 2017 in Sweden under the name The Single Malt Fund. This fund is the first regulated and publicly traded fund to offer investors an annual appreciation of $10 \%$ with an investment horizon of 6 years. The minimum amount that each investor must invest in the fund is EUR 1,000. [The Single Malt Fund, 16]

As part of the analysis and comparison, the main whiskey indices and global stock indices were selected and are listed in Table 1. Data and information were drawn from the websites on whiskey indices from Rare Whisky 101 [17] and on stock indices from Yahoo Finance [18].

Table 1. Examined financial indices and whiskey indices.

\begin{tabular}{|c|c|}
\hline $\begin{array}{c}\text { Financial } \\
\text { indices }\end{array}$ & $\begin{array}{c}\text { Whiskey } \\
\text { indices }\end{array}$ \\
\hline S\&P 500 & Icon 100 \\
\hline Nikkei 225 & Vintage 50 \\
\hline FTSE 100 & $\begin{array}{c}\text { Japanese } \\
\text { Incon 100 }\end{array}$ \\
\hline DAX & $\begin{array}{c}\text { Single Grain } \\
100\end{array}$ \\
\hline
\end{tabular}

Source: own processing

The analysis and comparison was performed with regard to the history of the existence of indices related to whiskey, including the determination of the examined time intervals for individual periods. The first indices related to this commodity, Icon 100 and Vintage 50, were established on 29 December 2008. They were followed by the establishment of the Japanese Icon 100 in 2014 and the latest one is the Single Grain 100 index, which was founded in 2017. The advantage of stock global indices is their long history, which the whiskey indices really lack so far. The oldest stock index examined here is the S\&P 500 from the USA, which was established in 1928, the second is the Nikkei 225 index from Japan, which was founded in 1965, followed by the FTSE 100 index from England with a date of establishment in 1984 and four years later, the DAX index was founded in Germany.

For the analysis and comparison of the results and historical performance, a short period lasting one year (from 1 September 2019 to 31 August 2020), a medium-term period of two years (from 1 September 2018 to 31 August 2020) and a long period of five years (from 1 September 2015 to 31 August 2020) were chosen. The results are shown in Table 2. For investors, this is an important criterion that facilitates decisions that are reflected in existing or newly created portfolios. By including this international commodity in the portfolio, it contributes to risk diversification, but many experts recommend that alternative 
investments account for a maximum of 10 to $15 \%$ in investment compositions, and this also applies to whiskey. After all, it is an alternative investment, the availability of which is not as limited as other non-traditional investments, such as precious stones or metals. Whiskey can be bought in almost all grocery stores, possibly focused on alcohol, but a customer usually buys it for direct consumption and not for investment purposes. It can also be purchased at auctions and exchanges. Whereas with other non-traditional investments, such as precious stones or metals, it is not so easy with availability. You cannot buy them so easily in regular stores.

A certain difficulty with whiskey investment is its appreciation in a longer time horizon lasting ten or more years. Some investors refer to it as a supplementary investment. On the other hand, we live in a global world where investment opportunities are expanding and the international environment is changing, as well as the behaviour of investors themselves. The financial and real investments that are on the course today are not guaranteed to continue to do so, because the international environment is very turbulent and volatile today.

Table 2. Analysis and comparison of the historical performance of the examined indices.

\begin{tabular}{|c|c|c|c|c|c|}
\hline \multicolumn{7}{|c|}{ Indices } & $\begin{array}{c}\text { Index } \\
\text { performance } \\
\text { for 1 year } \\
\text { (in \%) }\end{array}$ & $\begin{array}{c}\text { Index } \\
\text { performance } \\
\text { for 2 years } \\
\text { (in \%) }\end{array}$ & $\begin{array}{c}\text { Average } \\
\text { performance } \\
\text { of the index } \\
\text { for 2 years } \\
\text { (in \%) }\end{array}$ & $\begin{array}{c}\text { Index } \\
\text { performance } \\
\text { for 5 years } \\
\text { (in \%) }\end{array}$ & $\begin{array}{c}\text { Average } \\
\text { performance } \\
\text { of the index } \\
\text { for 5 years } \\
\text { (in \%) }\end{array}$ \\
\hline S\&P 500 & 15.05 & 19.34 & 9.67 & 78.37 & 15.674 \\
\hline Nikkei 225 & 9.46 & 4.03 & 2.015 & 30.42 & 6.084 \\
\hline FTSE 100 & -20.37 & -20.32 & -10.16 & -4.03 & -0.806 \\
\hline DAX & 5.34 & 7.38 & 3.69 & 27.94 & 5.588 \\
\hline \multicolumn{7}{|c|}{ Stock indices } \\
\hline Icon 100 & 2.03 & 1.26 & 0.63 & 103.90 & 20.78 \\
\hline Vintage 50 & 16.79 & 31.73 & 15.865 & 154.20 & 30.84 \\
\hline $\begin{array}{c}\text { Japanese } \\
\text { Incon 100 }\end{array}$ & 22.89 & 62.35 & 31.175 & 181.47 & 36.294 \\
\hline Single Grain & 13.01 & 18.07 & 9.035 & x & x \\
\hline
\end{tabular}

Source: own processing

The results of Table 2 show that all the examined indices achieved a positive historical performance in the international environment, except for the FTSE 100 stock index, which showed a loss in all examined time intervals.

In the shortest period of only one year, the Japanese Incon 100 whiskey index achieved the highest performance, growing by almost $23 \%$. For stock indices, it was the S\&P 500 index, which appreciated by approximately $15 \%$. It should be borne in mind that the stock markets suffered large losses due to the coronavirus pandemic, mainly during 2020, but still managed to show positive results.

In the medium-term period of two years, it was again the same index concerning Japanese Icon 100 whiskey, which achieved the highest growth, namely $62.35 \%$, i.e. the 
average annual appreciation reached $31.175 \%$. It is again worth noting the index related to Vintage 50 whiskey, which rose by $31.73 \%$, and the average annual appreciation reached $15.865 \%$. As in the shortest period, as for stocks, the S\&P 500 index grew the most, increasing its value by $19.34 \%$.

In the longest time horizon, which lasted "only" five years, the whiskey indices clearly dominate in terms of performance. The highest growth was achieved by Japanese Icon 100, namely $181.47 \%$, where the average appreciation for the year reached $36.294 \%$, followed by Vintage 50 with a growth of $154.20 \%$ and on average for the year it is $30.84 \%$, and the third is again the Icon 100 whiskey index with a growth of $103.9 \%$ in five years, where the average value reached $20.78 \%$. The Single Grain 100 index has not been rated for the long period, as it was not established until 2017. The S\&P 500 global stock index ranked fourth with a growth of $78.37 \%$ in five years, where the average annual appreciation reached $15.674 \%$. Other investigated stock indices also showed positive results, such as the Nikkei 225 and Dax.

\section{Discussions}

The analysis and comparison brought new findings. One of the main new findings, which has been proven, was that whiskeys are appreciated already in a short period of time. This is evidenced by the results presented and achieved in Table 2. Although the opinions of experts speak of a longer holding time horizon for the appreciation of this commodity of ten years or more. On the other hand, investing in one commodity, such as whiskey, is high risk. Its positive performance is also due to the current situation in the world, as investors, after the stock market crashes, were looking for where to appreciate or protect free cash resources and investing in whiskey offers that. Nevertheless, it is important to diversify the portfolio. Global stock markets offer varied diversification, as an investor can invest in various stocks of companies on world stock exchanges. For some beginning and inexperienced investors, the performance of stock indices can be disappointing. However, who anticipated the global coronavirus pandemic in 2020, which is the main cause of the collapse of international stock markets? Despite this unfavourable situation, the examined stock indices showed positive results in addition to the FTSE 100 index. It should also be noted that stocks offer additional return to investors in the form of dividends. The issue of company dividend policy is addressed, for example; Gobulov et al., [19], He et al., [20], Sejkora and Duspiva [21]. Whiskey does not offer this benefit if an investor invests in this investment in real form, then a trader only achieves a return on capital.

As the global environment is changing, affecting the lives of people on the planet, the behaviour of investors is also changing. One of the reasons is the influence of information technologies and their extreme development. Today, there is a key question addressed: what else can be replaced into a dematerialized form, because it saves costs for companies and people. We can see it in stocks, where the electronic form is clearly preferred to the paper form. This phenomenon is also seen in some alternative investments, such as postcards and postage stamps. People prefer to send electronic messages and messages using electronic devices, because this service is much cheaper and more convenient. However, there are things that can never be replaced electronically, and this is an opportunity for some investment instruments, for some alternative investments such as whiskey. This is a great advantage for this alternative investment, as it is a globally known distillate for the majority of the world's adult population. However, they already lack awareness of their investment opportunities offered to investment audience.

The issue related to investing in whiskey certainly deserves more attention at both the practical and theoretical levels. There are certain ways in which the researched issue can be expanded and thus gain in popularity with the investment public. The expansion of 
a portfolio with non-traditional investments should be supported in the field of theory by publishing activities related to this area. The quality of publications should be complemented by practical experience from professionals who invest in this alternative investment. In the Czech Republic, there is an absence of comprehensive literary sources dealing with the issue of investing in alternative investments, and this is one of the main reasons why they are not as popular and known as investment plans in stocks and real estate.

This article was supported by the scientific research project of the Czech Sciences Foundation Grant No: 19-15498S.

This paper was supported by the Student Grant Competition (grant no. 16) of University of Pardubice in 2020 .

\section{References}

1. Chen, L., Han, Q., Qiao, Z., Stanley, E. (2020). Correlation analysis and systemic risk measurement of regional, financial and global stock indices. Physica A: Statistical Mechanics and its Applications, 542, 122653.

2. Kleine, J., Peschke, T., Wagner, N. (2020). Rich men's hobby or question of personality: Who considers collectibles as alternative investment? Finance Research Letters, 35, 101307.

3. Platanakis, E., Sakkas, A., Sutcliffe, Ch. (2019). Harmful diversification: Evidence from alternative investments. The British Accounting Review, 51(1), 1-23.

4. Lahmiri, S., Bekiros, S., Stavroyiannis, S., Babalos, V. (2018). Modelling volatility persistence under stochasticity assumptions: evidence from common and alternative investments. Chaos, Solitons \& Fractals, 114, 158-163.

5. Alaka, H.A., Oyedele, L.O., Owolabi, H.O., Oyedele, A.O., Akinade, O.O., Bilal, M., Ajayi, S.O. (2017). Critical factors for insolvency prediction: towards a theoretical model for the construction industry. International Journal of Construction Management, 17(1), 25-49.

6. Kraftová, I., Kašparová, L. (2017). Assessment of the financial health of regional emergency medical services in the Czech Republic using the BAMF model. Journal of Business Economics and Management, 18(2), 340-353.

7. Kuběnka, M., Myšková, R. (2019). Obvious and Hidden Features of Corporate Default in Bankruptcy Models. Journal of Business Economics and Management, 20(2), 368383.

8. Kuběnka, M. (2015). Predictive Ability of the Index of Creditworthiness. In E. Pastuszkova, Z. Crhova, J. Vychytilova, B. Vytrhlikova \& A. Knapkova (Eds.), Proceedings of the 7th International Scientific Conference Finance and Performance of Firms in Science, Education and Practice (pp. 795-804). Zlín: Tomas Bata University Zlin.

9. Defau, L., De Moor, L. (2020). The investment behaviour of pension funds in alternative assets: Interest rates and portfolio diversification. International Journal of Finance \& Economics, Early access.

10. Bernardo, M.R., Campani, C.H. (2019). Liability driven investment with alternative assets: Evidence from Brazil. Emerging Markets Review, 41, 100653.

11. Kräussl, R., Lehnert, T., Rinne, K. (2017). The search for yield: Implications to alternative investments. Journal of Empirical Finance, 44, 227-236. 
12. Lahmiri, S., Bekiros, S. (2018). Time-varying self-similarity in alternative investments. Chaos, Solitons \& Fractals, 111, 1-5.

13. Yang, X., Dong, X., Kong, Z., Jiang, Q., Wang, T. (2020). Research on the construction of a natural gas price index in China. Energy Strategy Reviews, 30, 100521 .

14. Novotný, J., Myšková, R. (2019). Investment in Land - Strategic Decision. In J. Nesleha, L. Marek, M. Svoboda \& Z. Rakovska (Eds.), Proceedings Paper of 16th Annual International Scientific Conference on European Financial Systems Location (pp. 426-433). Brno: Masarykova University.

15. Manavi, S.A., Jafari, G., Rouhani, S., Ausloos, M. (2020). Demythifying the belief in cryptocurrencies decentralized aspects. A study of cryptocurrencies time crosscorrelations with common currencies, commodities and financial indices. Physica A: Statistical Mechanics and its Applications, 556, 124759.

16. The Single Malt Fund (2020, August 25). Documents. https://www.thesinglemaltfund.com/documents/

17. Rare Whisky 101 (2020, September 4). Indices. https://www.rarewhisky101.com/indices

18. Yahoo Finance (2020, September 5). World Indices. https://finance.yahoo.com/worldindices

19. Gobulov, A., Lasfer, M., Vitkova, V. (2020). Active catering to dividend clienteles: Evidence from takeovers. Journal of Financial Economics, 137(3), 815-836.

20. He, J., Tian, X., Yang, H., Zuo, L. (2020). Asymmetric Cost Behavior and Dividend Policy. Journal Of Accounting Research, 58(4), 989-1021.

21. Sejkora, F., Duspiva, P. (2015). The Position of Management of Czech Joint-Stock Companies on Dividend Policy. Economics and Management, 18(2), 73-88. 